Available online at www.eccomasproceedia.org

Eccomas Proceedia COMPDYN (2021) 2352-2358

ECCOMAS

Proceedia
COMPDYN 2021

$8^{\text {th }}$ ECCOMAS Thematic Conference on Computational Methods in Structural Dynamics and Earthquake Engineering M. Papadrakakis, M. Fragiadakis (eds.)

\title{
POST-TENSIONED LOW DAMAGE CLT WALLS WITH REPLACEABLE HYSTERETIC DEVICES - CONCEPT, EXPERIMENTAL AND NUMERICAL CHARACTERIZATION
}

\section{Luca Pozza ${ }^{1}$, Luca Benedetti ${ }^{2}$, Valentina Tomei ${ }^{3}$, Barbara Ferracuti ${ }^{3}$, Maria Zucconi ${ }^{3}$, Claudio Mazzotti ${ }^{1}$}

${ }^{1}$ Department of Civil, Chemical, Environmental and Material Engineering (DICAM), University of Bologna

Viale Risorgimento 2, 40136, Bologna, Italy

\{luca.pozza2, claudio.mazzotti\}@unibo.it

${ }^{2}$ CIRI Buildings and Construction (CIRI-EC), University of Bologna

Via del Lazzaretto 15/5, 40131, Bologna, Italy

\{luca.benedetti12\}@unibo.it

${ }^{3}$ Department of Engineering "Niccolò Cusano"

Via Don Csrlo Gnocchi 3, 00166 Rome, Italy

\{valentina.tomei, barbara.ferracuti, maria.zucconi\}@unicusano.it

\begin{abstract}
This paper deals with the conception, the experimental and numerical characterization of an innovative post-tensioned CLT wall system equipped with external and replaceable hysteretic devices. The cyclic behavior of the post-tensioned walls was firstly investigated at the mechanical laboratory of CIRI-EC of University of Bologna by means of experimental tests on single component of the structural system and on the full-scale post-tensioned CLT walls prototypes. Results from experimental tests demonstrate the capability of the conceived post-tensioned wall systems to withstand significant drift without damage on the main timber and steel components. A good dissipative capacity of the wall configurations equipped with dissipaters was also observed. A nonlinear Finite Element model capable of reproducing the wall system hysteretic behavior was developed in the OpenSees framework. Implemented FE numerical model demonstrated a good capability of reproducing the experimental response.
\end{abstract}

Keywords: CLT walls, Experimental test, Hysteretic devices, Numerical Model, Post-tension 


\section{INTRODUCTION}

The growing diffusion of timber buildings in seismic areas drawn the scientific community's attention to this kind of structures[1-4], leading to the conception of structural solutions able to preserve the buildings after a seismic event. To this aim, low damage post-tensioned technologies were introduced [5-8], which entrust the horizontal load to rocking dissipative timber walls. The rocking behavior is mainly controlled by PT (Post-Tensioned) bars positioned into cavities in the walls, fixed at the base and connected at the top of the wall, that control the recentering of the system. The dissipative contribution is devoted to hysteretic dampers, simply replaceable after a seismic event, connecting the base wall to the foundation $[9,10]$ or adjacent timber elements along elevation [10,11]. This paper deals with the experimental characterization, and numerical investigation of an innovative post-tensioned CLT wall system, equipped with external and replaceable hysteretic dampers. The investigated wall system was conceived referring to previous experience on GluLam and LVL post-tensioned technology available in literature $[5,6,12]$ and then improved adapting the system to the use of CLT panel $[7,8]$ and external replaceable hysteretic dampers [9].

The cyclic behaviour of the post-tensioned walls was investigated at the mechanical laboratory of CIRI-EC of University of Bologna by means of experimental tests on a single component of the structural system and on the full-scale post-tensioned CLT walls prototypes. Results from experimental tests demonstrated the capability of the conceived post-tensioned wall system to withstand significant drift without damage to the timber elements. A good dissipative capacity was also observed, mainly due to the entering into the plastic field of the dampers, which result severely damaged and easily replaceable.

A nonlinear Finite Element model capable of reproducing the wall system cyclic behaviour was developed in the OpenSees framework. The implemented FE numerical model demonstrated a good capability to reproduce the experimental response, resulting in an efficient tool for simulating the response of the entire building realized using the developed technology.

\section{EXPERIMENTAL CAMPAIGN}

The analyzed configuration is characterized by a single dissipative rocking wall connected to GluLam boundary columns. The GluLam columns are assumed to be part of a timber frame aiming to resist to vertical loads, while the CLT PT-wall system preserves the building against the horizontal action. The boundary columns were thought to be connected to the inter-floor beams, to avoids their direct connection with the rocking wall, that could lead to vertical displacements incompatible with the diaphragm system, as suggested by previous authors [12]. The rocking behavior is entrusted to the PT-bar and the dissipative contribution is devoted to hysteretic dampers. In particular, two pairs of dampers are placed along the base of the wall, working predominantly in the axial direction (axial dampers), and two pairs of dampers are positioned at the wall/column interfaces, working predominantly in the transversal direction (shear dampers). In addition, a post-tensioned only configuration (with no dampers) was considered, to highlight the dissipative and resistant contribution of the dampers. The PT-bars are also positioned in columns to simulate the presence of axial load.

The adopted hysteretic dampers are the so-called X-brackets $[10,13]$, which was conceived to be employed both as axial and shear dampers. At the component level, tests were conducted to characterize the connection system developed for the fastening of the hysteretic dampers to the CLT panel adopting a superficial FRP reinforcement [14]. Results demonstrated the effectiveness of the fasting system, especially with regard to the replaceability of the hysteretic dampers. At the system level, the single wall configuration with boundary columns was considered with an initial post-tension load of $350 \mathrm{kN}$. Figure 1 reports the test setup, the sample's geometry, 
and the cyclic protocol used to impose the top displacement to the wall, evaluated according to UNI EN 12512 [15], reaching 1.5\% drift. The CLT panel was realized with C24 wood layers, while the initial PT (Post-Tensioned)- Force was conferred through a dywidag steel bar ("www.dywidag-systems.com/emea") of $32 \mathrm{~mm}$, characterized by a modulus of elasticity of $205 \mathrm{GPa}$ and a yielding stress of $950 \mathrm{MPa}$. In addition, the X-Brackets are characterized by steel S275 and a thickness of $8 \mathrm{~mm}$.

The horizontal cyclic displacement was applied to the system by means of an hydraulic actuator with a capacity of $1000 \mathrm{kN}$, positioned at 3.1 from the wall base, while the initial PT force was applied to the PT-bars by means of a hydraulick jack. Furtermore, the horizontal loads were measured during the test togheter with the PT forces. These records are essential for the reconstruction of the global responce of the system. Moreover, in order to obtain information on the local responce of the system, Linear Variable Displacement Transducers (LVDTs) were employed to measure displacements in crucial points of the system, as shown in Figure 1. In particular, one LVDT was positioned in correspondence of the actuator, to record the displacements imposed to the system; two LVDTs measured the slip between the wall and the steel foundation; eight LVDTs measured the base uplifts of the wall and columns, in order to derive the neutral axis dephts; two LVDTs measured the vertical slip between column to wall interfaces.

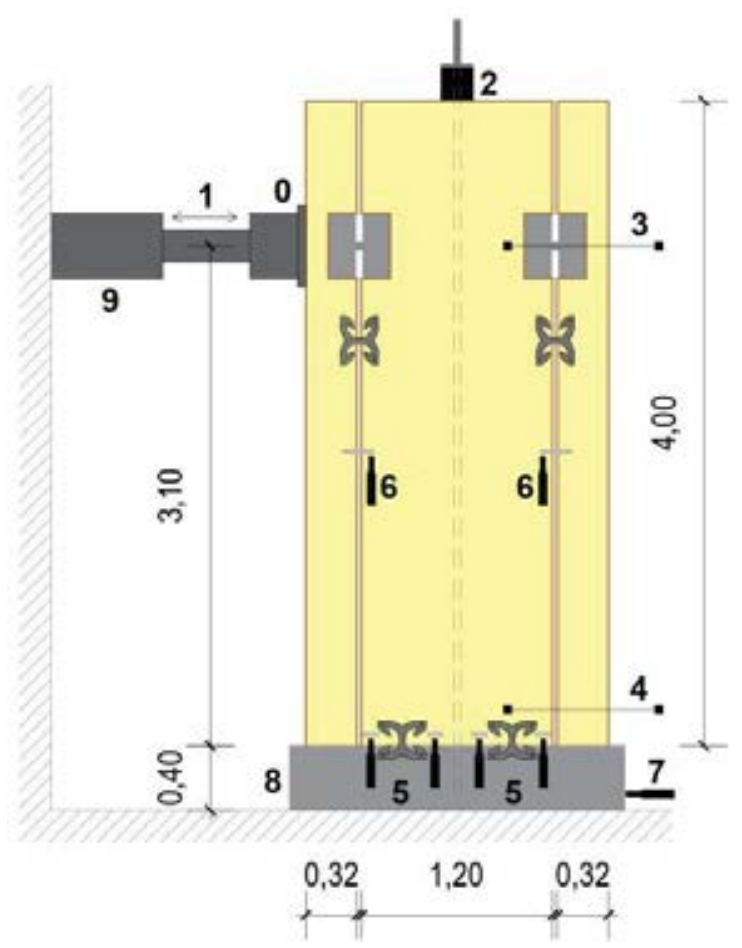

0) ACTUATOR'S LOAD CELL

1) ACTUATOR'S LVDT

2) POST-TENSIONED BAR'S LOAD CELL

3) WIRE INSTRUMENT - TOP

4) WIRE INSTRUMENT - BASE

5) NEUTRAL AXIS DEPTH LVDTS

6) WALL-COLUMN LVDT

7) RIGID BASE BEAM'S LVDT

8) RIGID BASE BEAM

9) $1000 \mathrm{kN}$ HYDRAULIC ACTUATOR

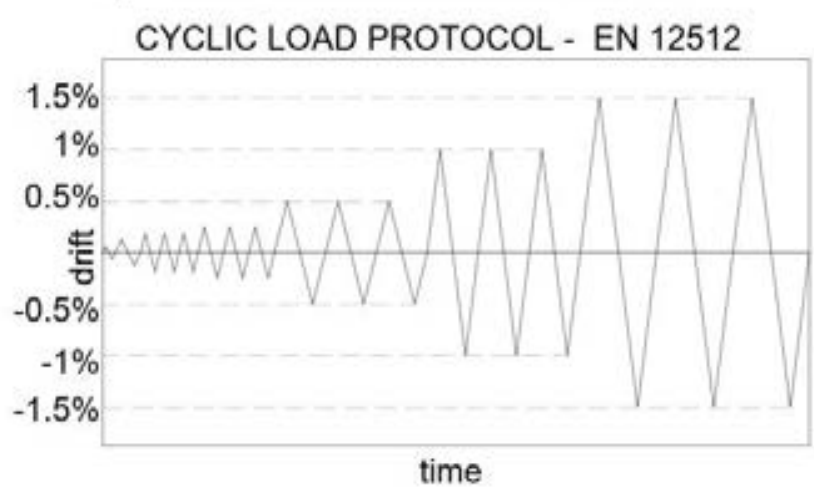

Figure 1: Column-wall-column test setup and adopted load protocol.

At tile of example, Figure 2 (a) show the view of the PT configuration equipped with both axial dampers (framed in red) and shear dampers (framed in blue). In Figure 2(b), global results in terms horizontal load/ drift curves are shows for the PT configuration (red) and for the PT configuration with dampers (blue). The two curves show an almost bilinear trend, more evident for the PT configuration, which transition point represents the drift at which the PT bar in the wall starts to deform. From the comparison between the two curves, it clearly emerges the contribution of dampers in terms of energy dissipation and strength, appreciable through the amplitude of the cycles and the horizontal load values reached with the same drift, respectively. 


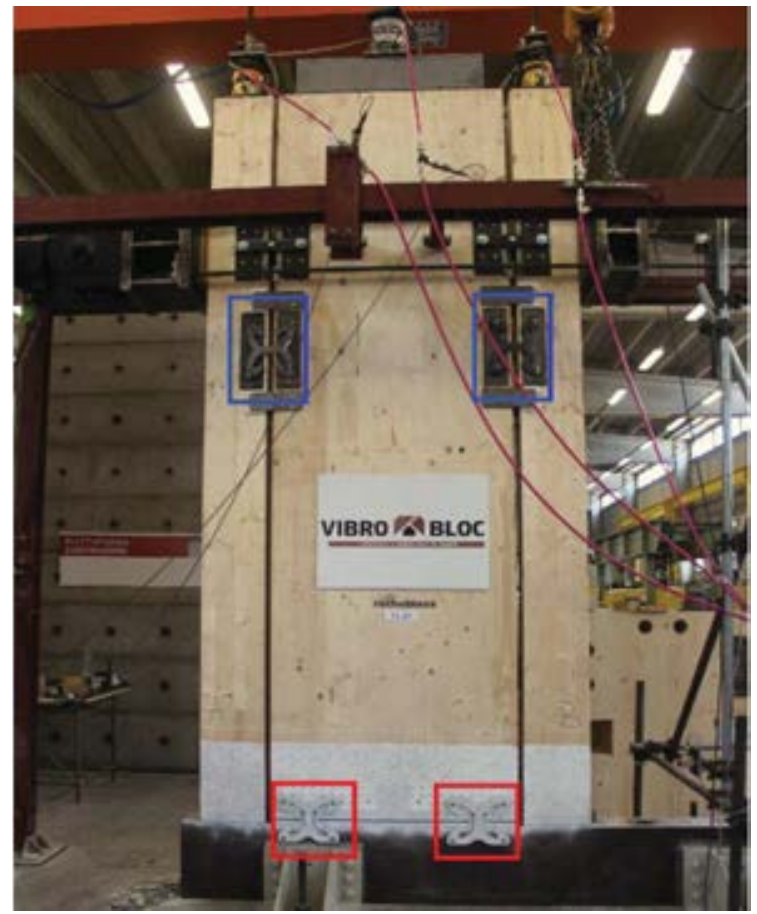

(a)

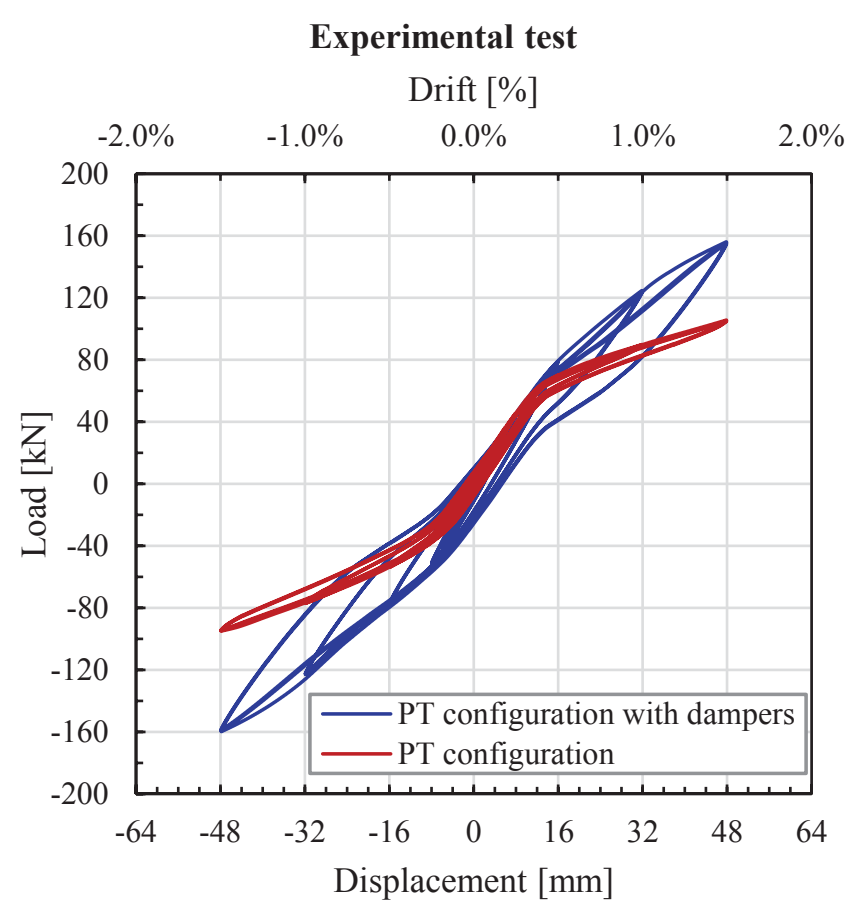

(b)

Figure 2: (a) View of the setup and (b) Experimental Horizontal load - Drift curves.

\section{EXPERIMENTAL AND NUMERICAL RESULTS}

In order to design, and then to simulate, the experimental campaign, a non-linear numerical model was developed in the OpesSees frame work[17]. The model took into account both geometrical and material non-linearities, the former due to the rocking behaviour of the system, and the latter due to the presence of axial and shear dampers. In particular, the behaviour of axial and shear dampers were calibrated on the base of experimental results obtained on the single components.

In this section, the main results of the experimental campaign are shown, compared with outputs of the numerical simulations. In particular, results obtained for the PT configuration (no dampers) and for the PT configuration equipped with axial and shear dampers are shown. Figure 3(a) and (b) report the horizontal load/ drift curves for the PT configuration and for the PT configuration equipped with dampers, respectively, highlighting their benefits in terms of energy dissipation and strength. The comparison between experimental and numerical results shows a good agreement in terms of initial stiffness, strength and cyclic behaviour. However, a slight underestimation of the cyclic behavior can be observed in the numerical simulations, mainly due to some frictional dissipation neglected in the numerical model.

The good agreement between experimental and numerical results is also confirmed by comparing the local behavior of the system, particularly on the wall uplifts measured along the base at the height of $20 \mathrm{~cm}$ shown in Figure 4. Furthermore, this plot helps to understand the behavior of the PT-bars, which, during the wall rocking, was subjected to elongation, and so to a PTforce increase, to accommodate the kinematic of the system. Figure 5 (a) shows the comparison between the experimental and numerical column to wall vertical slip versus drift, in which the left column, the wall and the right column are denoted as $\mathrm{C} 1, \mathrm{~W}$ and $\mathrm{C} 2$, respectively. This comparison show a good agreement between results, even if the numerical model slightly overestimated vertical slips. These results are of particular interest, since the dissipative contribution of the shear dampers maily depends on the colum to wall vertical slip; it is therefore possible 
to find information on the behavior of dampers even if it is not directly investigated from an experimental point of view. In this regard it is also useful to analyze some results carried out by the numerical model: as an example, the Figure 5 (b) shows numerical vertical slip/ shear force curves of the pair of shear dampers connecting the left column with the wall. In particular, it is evident that the shear dampers work in the plastic field ensuring a strong contribution in terms of energy dissipation; furthermore, it was predominantly exploited in one direction. In fact, due to the rocking behavior, when the system is pulled, the vertical slips between the left column and the wall is reduced, due to the limited width of the column, compared to that observed when it is pushed. The opposite is observed for the vertical slips between the wall and the right column.

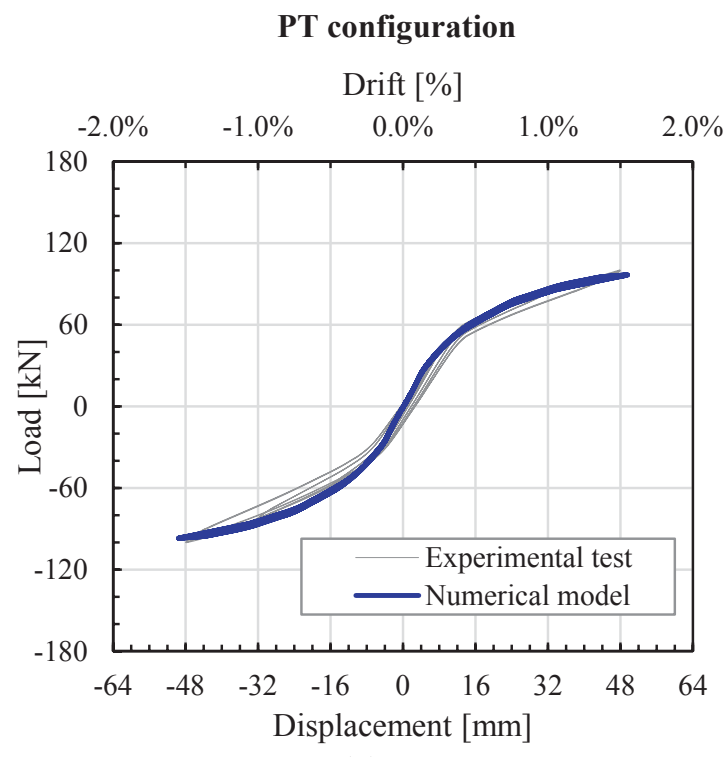

(a)

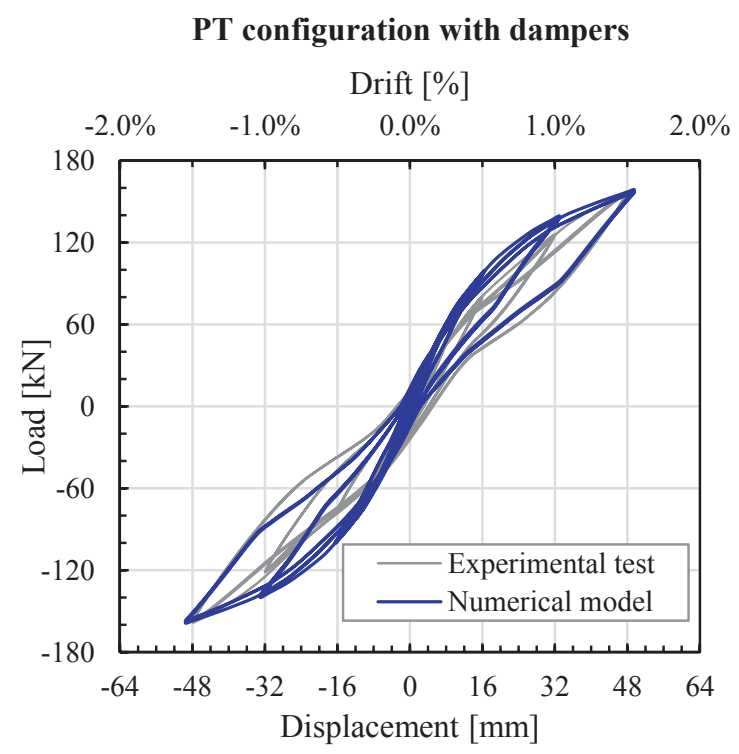

(b)

Figure 3: Horizontal Load-Drift curves: (a) PT configuration; (b) PT configuration with dampers.



Figure 4: Base vertical uplifts: PT configuration. 


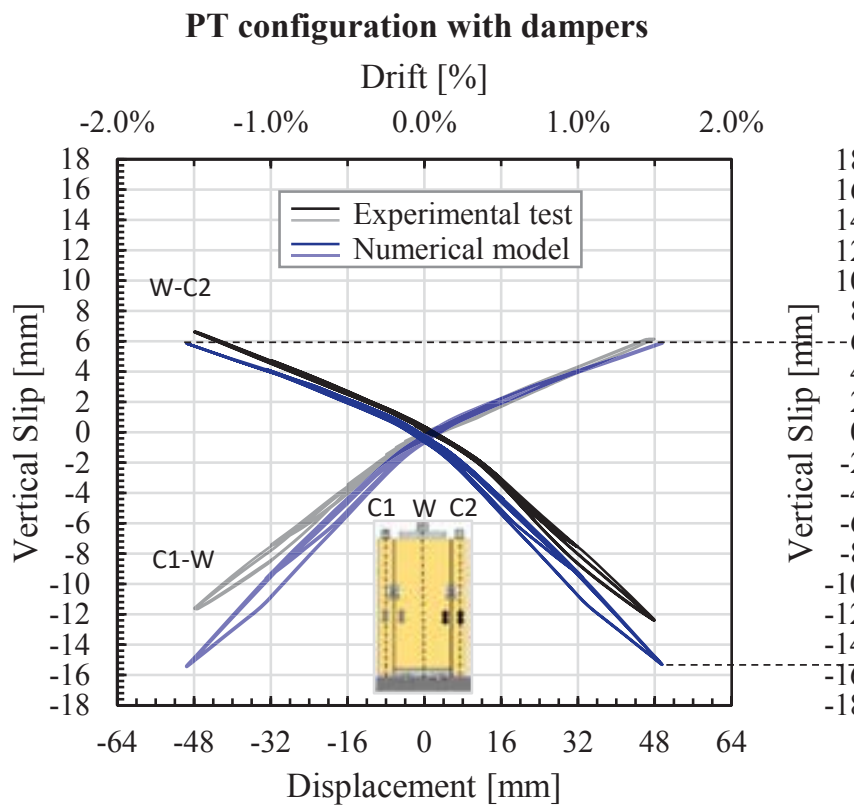

(a)



(b)

Figure 5: (a) Vertical slip/ Drift curves for the PT configuration with damper; (b) numerical vertical slip/ dampers' shear force.

\section{CONCLUSIONS}

Results of an experimental campaign on post-tensioned CLT wall system equipped with external and replaceable hysteretic devices were reported in this paper, demonstrating the capability of the developed system to withstand significant drift, until $1.5 \%$, without damage in the structural timber elements and the principal connection systems. Moreover, a good dissipative capacity of the wall configuration equipped with both axial and shear dampers was observed, and the replaceability of the hysteretic dampers was also proved during the experimental campaign. Furthermore, a numerical model was specifically developed to predict the response of the proposed systems', considering the geometric and material non-linearities mainly due to the wall rocking behavior and to the hysteretic dampers. The proposed numerical model demonstrated a good capability of reproducing the experimental response both at global and local levels, and the ability to provide reliable prediction on behaviors not directly investigated during the experimental tests on the PT-wall system, such as the response of the hysteretic dampers. Therefore, it can be employed for the modelling of similar PT-wall systems supporting the design phase.

\section{AKNOWLEDGEMENT}

The financial support of TIRISICO Project (POR FESR 2014-2020 - Regione Emilia Romagna) and of (Italian) Department of Civil Protection (ReLUIS 2019-2021 Grant - Innovative Materials) are gratefully acknowledged. The Authors would like also to thank the partner companies Vibro-Bloc S.p.A., Fibrenet S.p.A. and Rothoblass S.r.l. for their support and Dr. Gianluca Ussia and Dr. Francesco Grandi for the kind cooperation.

\section{REFERENCES}

[1] A. Ceccotti, C. Sandhaas, M. Okabe, M. Yasumura, C. Minowa, and N. Kawai, SOFIE project $-3 \mathrm{D}$ shaking table test on a seven-storey full-scale cross-laminated building, 
Earthquake Engineering Structural Dynamics, 42 (13), 2013.

[2] I. Gavric, M. Fragiacomo, and A. Ceccotti, Cyclic behavior of CLT wall systems: Experimental tests and analytical prediction models, Journal of Structural Engineering, 2015.

[3] F. Asdrubali, B. Ferracuti, L. Lombardi, C. Guattari, L. Evangelisti, and G. Grazieschi, A review of structural, thermo-physical, acoustical, and environmental properties of wooden materials for building applications, Building and Environment, 2017.

[4] A. Sandoli, V. Tomei, B. Ferracuti, and M. Zucconi, Challenges on clt structures seismic response: Traditional vs low-damage systems, in 16th European Conference on Earthquake Engineering, 2018.

[5] A. Iqbal, S. Pampanin, A. Palermo, and A. H. Buchanan, Performance and design of LVL walls coupled with UFP dissipaters, Journal of Earthquake Engineering, 2015.

[6] F. Sarti, A. Palermo, and S. Pampanin, Quasi-Static Cyclic Testing of Two-Thirds Scale Unbonded Posttensioned Rocking Dissipative Timber Walls, Journal of Structural Engineering, 2016.

[7] R. Ganey et al., Experimental Investigation of Self-Centering Cross-Laminated Timber Walls, Journal of Structural Engineering,, 2017.

[8] M. Massari, M. Savoia, and A. R. Barbosa, Experimental and Numerical Study of TwoStory Post-Tensioned Seismic Resisting CLT Wall with External Hysteretic Energy Dissipaters, in Atti del XVII Convegno ANIDIS L’ingegneria Sismica in Italia, 2017.

[9] F. Sarti, A. Palermo, and S. Pampanin, Fuse-Type External Replaceable Dissipaters: Experimental Program and Numerical Modeling, Journal of Structural Engineering, 2016.

[10] R. Scotta, L. Marchi, D. Trutalli, and L. Pozza, A dissipative connector for CLT buildings: Concept, design and testing, Materials (Basel)., 2016.

[11] J. M. Kelly, R. I. Skinner, and A. J. Heine, Mechanisms of energy absorption in special devices for use in earthquake resistant structures., Bulletin of the New Zealand Society for Earthquak Engineering, 1972.

[12] F. Sarti, A. Palermo, and S. Pampanin, Development and Testing of an Alternative Dissipative Posttensioned Rocking Timber Wall with Boundary Columns, Journal of Structural Engineering, 2016.

[13] D. Trutalli, L. Marchi, R. Scotta, and L. Pozza, Capacity design of traditional and innovative ductile connections for earthquake-resistant CLT structures, Bulletin of Earthquake Engineering, 2018.

[14] A. Bellini, L. Benedetti, L. Pozza, and C. Mazzotti, Experimental characterization of monotonic and cyclic behavior of steel-to-CLT nailed joints strengthened with composite plies, Construction and Building Materials, 2020.

[15] UNI EN 12512, Timber structures. Test methods. Cyclic testing of joints made with mechanical fasteners. UNI. 2006. 2006.

[16] www.dywidag-systems.com/emea.

[17] F. McKenna, M. H. Scott, and G. L. Fenves, Nonlinear finite-element analysis software architecture using object composition, Journal of Computing in Civil Engineering, 2010. 